\title{
The process of implementing a new working method - a project towards change in a Swedish psychiatric clinic
}

\author{
Catrin Alverbratt ${ }^{1}$, Eric Carlström ${ }^{1,2}$, Sture Åström ${ }^{1,3}$, Anders Kauffeldt ${ }^{1}$, J ohan Berlin ${ }^{4}$ \\ 1. Department of Nursing, Health and Culture, University West, Trollhättan, Sweden. 2. Institute of Health and Care \\ Sciences, the Sahlgrenska Academy, University of Gothenburg, Gothenburg, Sweden. 3. Department of Nursing, Umeå \\ University, Umeå, Sweden. 4. Department of Social and Behavioural Studies, University West, Trollhättan, Sweden.
}

Correspondence: Catrin Alverbratt. Address: Department of Nursing, Health and Culture, University West, SE-461 86 Trollhättan, Sweden. E-mail: catrin.alverbratt@hv.se

Received: August 12, 2014

DOI : $10.5430 /$ jha.v3n6p174
Accepted: October 9, 2014

URL: http://dx.doi.org/10.5430/jha.v3n6p174

\section{Abstract}

The implementation of evidence-based methods in hospital settings is difficult and complex. The aim of the present study was to highlight the implementation process concerning a new working method, i.e. a new assessment tool, based on the International Classification of Functioning Disability and Health (ICF), among psychiatric nursing staff on five participating wards at a Swedish county hospital. Descriptive, qualitative data were collected through focus group interviews pre- and post-implementation. Data were analysed using directed content analysis, guided by Normalization Process Theory (NPT). The results revealed that just one of the five participating wards met the criteria for a successful implementation process. The results confirm previous studies showing the difficulty of implementation. Although participants agreed with the intention of the model, they were reluctant to apply it in practice. The implementation process seemed to be influenced by factors such as: time pressure; heavy workload; stress; lack of routines in using the tool; lack of nursing staff; as well as cultural characteristics and resistance to change.

\section{Key words}

Implementation, Normalization process theory, Psychiatric nursing, Sweden

\section{Introduction}

New working models are often introduced to improve the healthcare industry. Because publicly financed healthcare has been considered conservative, the need for renewal has been emphasized ${ }^{[1,2]}$. This is especially applicable to hospital organizations with long and old traditions. Such a context is found within psychiatric care, which has been described as suffering from conservative and backward-looking working methods ${ }^{[3]}$. In the present article, a new working method has been introduced in a psychiatric clinic at a hospital in Sweden. The aim of the present study is to highlight the implementation process concerning this new working method, i.e. a new assessment tool, the Daily Life Dialogue Assessment, DLDA ${ }^{[4]}$ based on the International Classification of Functioning Disability and Health (ICF) ${ }^{[5,6]}$, among psychiatric nursing staff at a Swedish county hospital. 


\subsection{Background}

According to de Jager, Oreg and Lowe and McIntosh, some important factors to consider before and during change processes are organizational cultures and their subcultures ${ }^{[7-9]}$. The workplace culture is multifaceted and constitutes a major influence on individuals, group behaviour, job satisfaction and quality of care ${ }^{[10]}$. Saame et al. mean that the care process may be influenced by the organizational culture, as it may vary across different departments and settings ${ }^{[11]}$. Another important factor to consider before and during change processes is staff members' resistance to change ${ }^{[12]}$, because such resistance may counteract new technology as well as implementation processes ${ }^{[13,14]}$. Van Achterberg et al. mean that factors such as attitudes, knowledge or organizational characteristics, etc., may be important for successful implementation or its opposite, resistance to change ${ }^{[15]}$.

\subsection{I mplementation}

There are several definitions of the concept of implementation. In summary, implementation is identified as the process from idea to practice, where the idea often is based on research results ${ }^{[16-18]}$. Thus, implementation is understood as the process of practically applying scientific knowledge ${ }^{[19]}$. Van Achterberg et al. emphasize that there are several examples of implementation failure in nursing practice ${ }^{[15]}$.

Implementation science is closely connected to the concept of evidence-based methods ${ }^{[20]}$. With regard to nursing, Van Achterberg et al. describe evidence-based methods, as the optimal use of research evidence ${ }^{[15]}$. Drake et al. define evidence-based practices in mental health service settings as "interventions for which there is consistent scientific evidence showing that they improve client outcomes” ${ }^{[21]}$. Torrey et al. mean that implementing evidence-based practices in mental health practice is difficult and complex ${ }^{[22-25]}$. Several psychiatric nursing care models have been implemented in healthcare, some more successfully than others ${ }^{[26-28]}$.

Chan et al. investigated the outcome of implementation of a case management model in a community psychiatric nursing service in Hong Kong. The results showed that the group of patients $(n=31)$ for whom the case management model was used were more satisfied and showed better outcomes in terms of functional level and mental status than the control group did $(n=31)^{[27]}$. Another successful intervention was described by Arvidsson et al., who investigated the outcomes of supervision during a nursing care programme. Four years after the supervision programme had ended, they found that the programme had influenced the nurses' professional competence and that the nurses' professional identity had been strengthened ${ }^{[26]}$. A less successful implementation is described by Lauritzen et al., who evaluated the implementation of a new legislation concerning the identification and follow-up of children of parents suffering from mental illness. The identification rate had increased but very slowly, and three years after the legislation was introduced, the new practice had still not been fully implemented ${ }^{[28]}$.

The International Classification of Functioning Disability and Health, ICF ${ }^{[5,6]}$, has been the subject of research for over a decade in a range of areas, however there are few studies describing implementation of the ICF in clinical settings ${ }^{\text {[29] }}$.

\subsection{I mplementation theories}

Different theories have been used to evaluate implementation or intervention in a hospital context. According to Carlfjord, theories, frameworks and models increase knowledge, facilitate evaluations and improve conclusions concerning whether or not an implementation or intervention has been successful ${ }^{[30]}$. One widely used innovation theory is Diffusion of Innovation (DOI) by Rogers ${ }^{[31-34]}$. DOI describes how an innovation is spread to an individual or throughout an organization using five stages along a time axis. These five stages are: knowledge, persuasion, decision, implementation and confirmation. The theory also uses the concept of change agents. The change agent's role is to deal with the innovation, or to prevent it from spreading, in order to protect the organization from unwanted effects that innovation might bring about ${ }^{[31-33]}$. 
Another widely used theory is Promoting Action on Research Implementation in Health Services (PARIHS) ${ }^{\text {[35-37]. }}$. PARIHS is a framework for successful implementation of evidence-based practice in healthcare. The theory consists of three key concepts, evidence, context and facilitation, each of which is placed on a continuum from high to low, and where the most successful implementation is expected to take place when all three elements are "high". Such successful implementation consists of scientific stability within a context that is receptive to changes, strong leadership and a culture that has a well-developed system of monitoring and feedback ${ }^{[36,37]}$.

The chosen theory for the present study was Normalization Process Theory, Normalization Process Theory (NPT) ${ }^{\text {[23-25] }}$. This choice is based on the assumption that NPT is a theory of action aimed at discovering how people work and what they actually do when something new is to be implemented. One of the reasons for developing NPT was that, in hospital settings, it is difficult to implement changes that require new ways of working or new ways of organizing care ${ }^{[23-25]}$. The fact that NPT was developed for the hospital context is also a reason it was chosen for the present study.

NPT is derived from sociology and uses three key concepts to explain and understand the social processes of adopting, thinking about and organizing work in healthcare settings when new routines or new practices are to be implemented. The three key concepts of NPT are; implementation, embedding and integration. Implementation refers to the social parts of the organization that are affected when something new is implemented. Embedding refers to the processes that enable a new practice to become incorporated into daily work. Integration is about the processes taking place when something new is reproduced and maintained in the organization. According to NPT, whether or not a change will be routinely embedded depends on the individuals at each specific unit. The likelihood of embedding taking place may be identified through four mechanisms or components: coherence, cognitive participation, collective action and reflexive monitoring. These are influenced by factors that facilitate or inhibit the embedding of a new routine or new way of working at the current units ${ }^{[23-25]}$.

Table 1. Coding frame for implementation of the DLDA, according to normalization process theory ${ }^{[52]}$

\begin{tabular}{|c|c|c|c|}
\hline $\begin{array}{l}\text { Coherence "The significant } \\
\text { qualities DLDA" }\end{array}$ & $\begin{array}{l}\text { Cognitive participation } \\
\text { "Enrolment and engagement } \\
\text { of individuals and groups" }\end{array}$ & $\begin{array}{l}\text { Collective action "Interaction } \\
\text { with already existing practices" }\end{array}$ & $\begin{array}{l}\text { Reflexive monitoring "How } \\
\text { a practice is understood } \\
\text { and assessed by actors } \\
\text { implicated in it" }\end{array}$ \\
\hline $\begin{array}{l}\text { Differentiation: Understanding } \\
\text { the difference between DLDA } \\
\text { and “the old fashion way" of } \\
\text { working in a psychiatric } \\
\text { nursing context }\end{array}$ & $\begin{array}{l}\text { Initiation: The participants' } \\
\text { motivation in trying to } \\
\text { incorporate the DLDA tool }\end{array}$ & $\begin{array}{l}\text { Interactional workability: Operating } \\
\text { DLDA }\end{array}$ & $\begin{array}{l}\text { Systematization: The } \\
\text { participants' judgment of } \\
\text { DLDA regarding usefulness } \\
\text { and effectiveness }\end{array}$ \\
\hline $\begin{array}{l}\text { Communal specification: The } \\
\text { process in which the users } \\
\text { through teamwork share and } \\
\text { create an understanding of this } \\
\text { new practice }\end{array}$ & $\begin{array}{l}\text { Enrolment: The work the } \\
\text { participants do to organize } \\
\text { themselves and their co-workers } \\
\text { to participate in the practice of } \\
\text { DLDA }\end{array}$ & $\begin{array}{l}\text { Relational integration: Participants' } \\
\text { understanding of DLDA, not only } \\
\text { being aware of how and when to use } \\
\text { the DLDA (knowledge), but also } \\
\text { understanding the expressions of } \\
\text { other staff members }\end{array}$ & $\begin{array}{l}\text { Communal appraisal: } \\
\text { Communal appraisal } \\
\text { regarding the outcomes and } \\
\text { value of DLDA }\end{array}$ \\
\hline $\begin{array}{l}\text { Individual specification: The } \\
\text { process in which the users } \\
\text { create an understanding of this } \\
\text { new practice }\end{array}$ & $\begin{array}{l}\text { Legitimation: The belief that } \\
\text { DLDA is right for the context in } \\
\text { terms of being a needed } \\
\text { complement to existing tools } \\
\text { and approaches }\end{array}$ & $\begin{array}{l}\text { Skill-set workability: Refers to how } \\
\text { to the DLDA is conducted and } \\
\text { distributed. This will influence how } \\
\text { the work is defined and divided } \\
\text { among participants }\end{array}$ & $\begin{array}{l}\text { Individual appraisal: } \\
\text { Individual appraisal } \\
\text { regarding the outcomes and } \\
\text { value of DLDA }\end{array}$ \\
\hline $\begin{array}{l}\text { Internalized meaning: The } \\
\text { coherence of DLDA was based } \\
\text { on the meaning the users } \\
\text { collectively invest in it }\end{array}$ & $\begin{array}{l}\text { Activation of DLDA: What the } \\
\text { participants could do together to } \\
\text { improve conditions for DLDA to } \\
\text { be sustained and become a part } \\
\text { of daily practice }\end{array}$ & $\begin{array}{l}\text { Contextual integration: The } \\
\text { incorporation of DLDA into a social } \\
\text { context on the current wards }\end{array}$ & $\begin{array}{l}\text { Reconfiguration: Suggestions } \\
\text { from participants that aim to } \\
\text { modify and enhance the } \\
\text { utility of the DLDA tool }\end{array}$ \\
\hline
\end{tabular}

The components of coherence, cognitive participation, collective action and reflexive monitoring have all four subcomponents each; they will serve as key concepts and form the basis for the coding framework in the present study (see 
Table 1). Coherence concerns the significant qualities of a new method or new way of working. Cognitive participation could be explained as the engagement and enrolment of groups and individuals. Collective action could be summarized as how the new practice interacts with already known and existing practices. Reflexive monitoring concerns how this new way of working or new method is assessed and understood by the participants. Implementation can be summarized as a process containing four steps, starting with coherence, cognitive participation, collective action and, if the implementation is fully successful, ending with reflexive monitoring ${ }^{[23-25,38]}$. Because NPT has been developed for the healthcare industry and has been used to analyse implementation processes in hospital contexts, it is thought to be a useful conceptual tool for use in the present study and for understanding the implementation, embedding and integration of the DLDA tool in a psychiatric nursing context ${ }^{[38]}$.

\section{Method}

\subsection{Context}

During autumn 2011, a project towards change was planned on several psychiatric inpatient and outpatient wards at a Swedish county hospital. The project consisted of the implementation of a new assessment tool, the DLDA ${ }^{[4]}$. The assessment tool was based on the ICF's component of Activities and Participation ${ }^{[5,6]}$. It represented a new way of working, focusing on patients' functions and patient participation. Development of the DLDA began back in 2007 when a psychiatric clinic in Sweden and University West began a collaboration to implement the ICF in clinical practice ${ }^{[4]}$. However, it was necessary to develop some kind of short version that included the most important ICF items in relation to the psychiatric nursing context. Because none of the already existing short versions, such as core sets, checklists or disability assessment schedules ${ }^{[39-41]}$, were appropriate for the current clinical practice, a non-validated ICF-based assessment tool was developed ${ }^{[4]}$.

The wards participating in the present study had also been studied in 2011 regarding their organizational cultures and resistance to change ${ }^{[42]}$. The results revealed a culture dominated by properties such as flexibility, trust and cohesion. The study also revealed low levels of resistance to change ${ }^{[8]}$. The participating units were represented by three inpatient wards and one outpatient unit. All wards but one (Ward 3) were characterized by these properties. Ward 3 had an almost equal mix of all cultural characteristics included in the theoretical model used, yet showed the highest mean value for a culture of stability and control of all the studied wards. The present study was represented by the same inpatient and outpatient units that participated in Johansson et al., study ${ }^{[42]}$. However, one additional outpatient unit participated.

\subsection{Focus group interviews}

This is a descriptive study based on qualitative data, collected through focus group interviews ${ }^{[43,44]}$ conducted pre- and post-implementation of the DLDA tool ${ }^{[4]}$. To investigate the process of implementing the DLDA and to learn more about outcomes from a nursing perspective, seven focus group interviews were conducted with a total of 19 psychiatric nursing staff. Six of them participated at both occasions, pre- and post-implementation. Focus group interviews are a common method when gathering qualitative data in a healthcare context ${ }^{[45,46]}$. They are often semi-structured group interviews focusing on a specific topic or specific issues and led by a moderator who asks open-ended questions and encourages participants to interact in discussions relevant for the overall aim of the focus group interview ${ }^{[46-48]}$. In the present study, the focus group interviews were held at the studied hospital and its outpatient units. The interviews lasted between 34 and 75 minutes each. They were audio-taped and then subsequently transcribed verbatim. Prior to implementation, the focus group interviews started with an open-ended question: "Please describe your experiences of making function assessments in psychiatric nursing today". The interviews that took place after implementation of the DLDA tool and consisted of questions regarding outcomes and experiences. The moderator's role was to introduce specific topics without leading the focus group in directions that could confirm existing expectations and to provide participants with open-ended questions during the interview ${ }^{[49]}$. The moderator also declared at the beginning of each interview that she was there to listen and 
learn from the participants ${ }^{[45]}$. Immediately after each focus group, the moderator made notes on the interview ${ }^{[50]}$. Data were analysed using directed content analysis ${ }^{[51]}$. In order to analyse the implementation process at the participating units, NPT was used ${ }^{[23-25]}$. According to Carlfjord, theories can be used to form a grid of and to identify important factors affecting the implementation process ${ }^{[30]}$.

\subsection{Participants}

A total of 21 key participants represented by assistant nurses, registered nurses, psychiatric specialist nurses (hereafter called nurses) and occupational therapists from five participating units (hereafter called wards) at a Swedish county hospital participated in the study. The focus groups provided a general picture of the participating inpatient as well as outpatient wards, including the perspectives of different professionals prior to implementation. The key participants' role was to take part in a training programme that would allow them to implement a new working method ${ }^{[4,31-33]}$. The training programme consisted of training in the ICF and the DLDA tool. Since there were just six participants at both focus group interviews occasions, they were complemented with other key participants who had been trained in the ICF and DLDA tool.

\subsection{Data collection and analysis}

In September 2011, prior to implementation of the DLDA tool, two focus group interviews with five and four key participants, respectively, were held. Both were divided into an inpatient group and an outpatient group. Approximately a year after the training programme and implementation of the DLDA tool, at the end of 2012 and the beginning of 2013, new focus group interviews were held to assess the current situation. Because projects towards change and resistance to change may vary across wards and workplaces ${ }^{[42]}$, we found it important to interview the key participants on each ward separately. The interviews were held on each ward (1-5) in order to discover how the implementation process had proceeded. Focus group interviews on Ward 1-3 represented psychiatric inpatient care and Ward 4-5 represented psychiatric outpatient care. The numbers of participants ranged from 2-6 (see Table 2).

Table 2. Overview of focus group interviews

\begin{tabular}{lllll}
\hline & Inpatient ward/s & Outpatient ward/s & Number of participants & Date of Interview \\
\hline Pre-implementation & & & & \\
Focus group: I & $\mathrm{x}$ & $\mathrm{x}$ & 5 & September 2011 \\
Focus group: II & & & 4 & September 2011 \\
Post-implementation & & & 3 & \\
Focus group: Ward 1 & $\mathrm{x}$ & 2 & December 2012 \\
Focus group: Ward 2 & $\mathrm{x}$ & & 2 & December 2012 \\
Focus group: Ward 3 & $\mathrm{x}$ & $\mathrm{x}$ & 6 & December 2012 \\
Focus group: Ward 4 & & $\mathrm{x}$ & 2 & December 2012 \\
Focus group: Ward 5 & & &
\end{tabular}

The data were analysed using directed content analysis ${ }^{[51]}$ and NPT ${ }^{[23-25]}$. Key concepts in NPT guided the analysis and the coding framework, i.e. categories and subcategories ${ }^{[52]}$ (see Table 1). The coding of data began immediately after the interviews. Data that did not match the predetermined categories and subcategories were analysed at the end of the process to ensure the construction of new categories ${ }^{[51]}$.

\subsection{Ethical considerations}

Before the interviews, the participants received written information about the study and were told that participation was voluntary. The names of the participants were substituted in the transcript, as well as other information that might reveal their identity. The study was approved by the local ethical review board at University West (reg. no.: 2011/712 B22). The study complied with the ethical procedures stipulated by Swedish law ${ }^{[53]}$. 


\section{Results}

\subsection{Pre-implementation of the DLDA}

The two focus group interviews performed pre-implementation required that almost all key participants were already aware of the ICF - knowledge the participants acquired to become a nurse or specialist nurse. However, they stressed that knowledge of the ICF was very limited among their colleagues on the wards. The participants revealed that although the ICF was beneficial, it was hard to use. They did, however, like the idea that the ICF focuses on patients' functions instead of on diagnosis. They confirmed the importance and usefulness of the ICF, even if it had not yet been applied on any of the participating wards.

“No, I haven't encountered it so much (...), but it will be exciting, I think it will be good... If it works, if everyone learns. And if everyone wants and if everyone thinks it’s positive. It will be good enough.” Lisa, Ward 3.

Regarding assessment of patients' functioning, the participants described different strategies. Participants from Focus Group II seemed more familiar with assessing patients' functioning than the others were. Some of the participants used to print out information on patients' current (medical) status from the documentation system. One of the participants reported that she was already used to focusing on functions. In order to get a picture of patients' functioning, she used a whiteboard (together with the patient) to write down his/her functions, where patients functions emerged. Another participant felt there was no structure in the dialogue with patients on this ward, but this participant was guided by one overall question: How is the person's life? A third participant revealed that she was used to giving patients homework, asking them to describe their current situation. A difficulty that emerged was that it could be difficult for nursing staff to know how well the patient's perceptions correlated with reality. The participants' experience of new working models implemented prior to implementation of the DLDA revealed difficulties. The participants from Ward 4 considered the crucial factor for successful implementation to be having a clear purpose and that the model replaced current routines. Participants who represented Ward 1, 2 and 3 expressed their awareness that staff may respond negatively to changes, which may contribute to difficulties when implementing something new.

"Change, it's difficult. (...) The staff can be divided into two groups; one group that is more ambitious and really wants to move on and the other that doesn't dare to go further and try new things. (...) Change is not always considered a positive thing.” Annika, Ward 1.

One motivating factor was that the participants were not comfortable with the traditional classification of the ICF. That was a reason why they were open to something new. The participants hoped for an adapted tool that was easier to use than the traditional classification - a tool that could clearly identify what help the patient needed.

\subsection{Post-implementation of the DLDA}

In order to evaluate the implementation process, new focus group interviews were performed about a year after introduction of the DLDA tool.

\subsubsection{Coherence}

Coherence concerns the meaningful qualities of a practice, and the data showed that the concept of coherence was included in most of the statements. It was divided into four subcategories: differentiation, communal specification, individual specification and internalized meaning. Staff on all of the participating wards (1-5) made statements connected to these four subcategories.

Some of the participants expressed frustration that, in psychiatric care, diagnosis takes priority over function. They emphasized the importance of taking into account the social network, family and social problems, housing, finances, contacts with local authorities and social services. Therefore the DLDA tool was considered useful because it focuses on functions and daily life. The participants also meant that simple everyday things, easily overlook by professionals, were 
facilitated by using the DLDA. The tool was also a suitable basis for care planning, though this had not yet been tested on any of the participating wards. However, the work to get other staff members to participate proved to be difficult in some departments. Another difficulty was making assessments of patients simply by talking to them; they preferred performing more observations of the patient. Below follows descriptions and quotes from staff on the participating wards concerning the subcategories of Coherence; Differentiation; Communal Specification; Individual Specification and Internalized meaning.

\subsubsection{Differentiation}

Most statements were found among the subcategory differentiation, which reflects participants who displayed great understanding of how the DLDA tool differed from traditional psychiatric nursing. Overall, participants thought that the DLDA represents a mindset for focusing on patients' functions in psychiatric care. It was also considered to be a useful basis for care planning. Participants on Ward 1 and 2 meant that the DLDA was a useful tool for identifying patients' strengths, not just their limitations, where the latter was thought to be common practice.

"We have to focus on possibilities, not just obstacles. It's easy to focus only on the negative, but to take advantage of the positive ...” Amanda, Ward 2.

Ward 4 and 5 stated that the DLDA was useful for dialogue, which was otherwise easily overlooked.

\subsubsection{Communal specification}

Communal specification "was the process in which the users through teamwork share and create an understanding of a new practice". The participants representing Ward 1 revealed that most of their colleagues had acquired a new way of thinking when they encounter new patients. This new way was represented by a functional mindset in which the nursing staff saw the patients not only based on their diagnosis, but also their everyday functions. This also occurred on Ward 2, where the participants had started to focus more on patients' functions since introduction of and training with the DLDA. On the other hand, on Ward 3 the participants expressed their frustration that the diagnosis was still more important than functioning. Although the new way of thinking on Ward 1 and 2 could be interpreted as a mindset characterized by the ICF, teamwork regarding sharing and consequently using the DLDA tool was still problematic. Although there was resistance on Ward 3 in the beginning, with the help of additional information about the ICF and the DLDA staff members' understanding had improved.

“At the beginning, we weren't very positive (...).We felt that it required a lot of work (...). But gradually (...) I heard more staff who were positive about it.” Tanja, Ward 3.

Ward 5 revealed no problems at all with sharing and creating an understanding of the DLDA.

\subsubsection{I ndividual specification}

Individual Specification concerns the process through which users create an understanding of a new practice. Participants generally felt that the DLDA tool facilitated conversations and dialogues with patients. Ward 1 had also experienced the potential of empowering patients using the DLDA.

"When she filled in the DLDA instrument, she began to realize how much she could actually accomplish by herself.....then she started to be more positive about the instrument.” Malin, Ward 1.

Both Ward 2 and 3 had experienced a positive side effect of using the assessment tool, which mainly consisted of the patients' appreciation. The patients had started to appreciate having structured dialogues with their contact person.

\subsubsection{I nternalized meaning}

The internalized meaning of the DLDA was based on the meaning the users collectively invest in it. Staff on Ward 4 and 5 found it meaningful to use the tool several times at appropriate intervals on the same patient, in order to evaluate functions. 
One participant on Ward 5 had actually already evaluated the functions by letting patients perform the assessment a second time.

"It improves the communication (...) their shortcomings but also their resources appear (...). I think it's a good asset as a basis for discussion as well as follow-up.” Camilla, Ward 5.

Ward 1, 2 and 3, on the other hand, highlighted the DLDA tool as an aid in psychiatric nursing care because it encouraged patients to reflect. The tool was considered meaningful to use on inpatient wards as well as at outpatient service centres.

\subsection{Cognitive participation}

Cognitive participation concerns the enrolment and the engagement of individuals and groups in the process of implementing the DLDA. One reason, emphasized by several participants, was the slow implementation of DLDA due to lack of time, but also because they felt busy and sometimes understaffed. Under such circumstances, it was difficult to find enough time for the DLDA. Staff on one ward had tried to implement the tool among their colleagues and found it difficult to get any engagement at all. The resistance among participants and their colleagues may be due to the fact that not all nurses on the wards under study were allowed to participate in the training programme pre-implementation, or to the fact that implementation of the DLDA was part of a research study. However, on one of the five participating wards, implementation proceeded without problems. Despite the resistance and difficulty in incorporating the DLDA, all participants reported that the DLDA tool was appropriate to the psychiatric nursing context. The participants provided several suggestions on how to improve conditions to ensure the DLDA would be sustained and become part of daily practice. Below are descriptions and quotes from the participating wards concerning the subcategories Cognitive participation; Initiation; Enrolment; Legitimation and Activation of DLDA.

\subsubsection{I nitiation}

Initiation refers to participants' efforts, or lack thereof, to try to incorporate the DLDA tool. The participants on Ward 1 had tried to incorporate the DLDA tool by informing and showing their co-workers about DLDA and showing them the method at several occasions. Despite this, it had been difficult to implement it among colleagues on the ward; this was also experienced on Ward 2 and 3. On Ward 3, on the other hand, participants experienced that the response from co-workers had improved gradually. The work the participants on Ward 5 had done to incorporate the DLDA tool consisted mainly of providing information.

“... We are so stressed and the tempo is so high (...) the staff regard it as an extra burden imposed on them. Though it isn't really that way ...” Ann, Ward 2.

In general, the factors contributing to a slow implementation process were considered to be time pressure; heavy workload; stress; lack of any routine in using the tool and lack of nursing staff.

\subsubsection{Enrolment}

Enrolment concerns when the participants organized themselves and their co-workers to take part in practicing the DLDA. All but one ward (Ward 4) contributed statements related to this subcategory. On Ward 5, the DLDA tool was on its way to becoming part of daily work. More and more co-workers had started to use it together with their patients. In order to get their co-workers involved and practicing the DLDA, the participants on Ward 1, 2 and 3 had presented the tool and the workflow, however with meagre results.

"I said (...) just ask if you have any questions about the instrument, and I'll help you, but it never happened.” Annika, Ward 1.

On Ward 3, one participant used the DLDA tool by performing the DLDA assessment together with patients, thereafter documenting the results. 


\subsubsection{Legitimation}

Legitimation refers to a belief that the DLDA was appropriate to the context and a needed complement to existing tools. Staff on all of the inpatient wards $(1,2,3)$ were convinced that psychiatric nursing requires tools if they are to maintain routines and do an adequate job. The DLDA was seen as a useful and needed example of such a tool. Staff on Ward 5 also emphasized the suitability of the DLDA tool.

“... I could use it for all my patients, (...). Because I think it's great for discussion.” Maria, Ward 4.

Besides this, staff on Ward 4 also emphasized the qualities of the tool, but they were convinced that actual accomplishment must take place in forms other than those used during the research project.

\subsubsection{Activation of the DLDA}

Activation refers to what the participants could do together to improve conditions for the DLDA to be sustained and become a part of daily practice. Staff on all wards but Ward 5 made statements related to this subcategory. Reminders, tutoring and information were considered important cornerstones in improving conditions for the DLDA to become part of daily practice. Ward 1 emphasized tutoring, where key participants would instruct and guide their co-workers, as well as involving other professionals, such as doctors on the ward. Tutoring was also emphasized on Ward 4, where participants suggested recurrent training sessions each semester, allowing employees to come and listen and update themselves about the latest knowledge regarding functional assessments. Another important factor discussed by staff on Ward 4 was improving how the DLDA was documented. Staff on Ward 2 and 3 needed to improve procedures in order to fully activate the use of DLDA.

\subsection{Collective action}

Collective action concerns the interaction with already existing practices. The participating wards had slightly different ways of operationalizing the DLDA. Ward 1 did not operationalize the DLDA tool in practice, but they did operationalize an approach characterized by the ICF during their morning meetings with all nursing staff, where they nowadays discuss patients' functioning. On Ward 4, the DLDA was used as an unstructured dialogue tool. The staff on this ward felt that the DLDA could be used with both new and already known patients. This statement was also made by participants on Ward 5, where the DLDA was used each time they met with a new patient. In this category, collective action included the subcategories: Interactional workability; Relational integration; Skill-set workability and Contextual integration. Here we see the statements by staff on the wards beginning to fade: Ward 1 and 2 had no statements at all related to this category.

\subsubsection{I nteractional workability}

This subcategory identifies how participants operationalized the DLDA tool. On Ward 4, the DLDA was used as a dialogue tool and served as an inspiration for questions and conversations. Some of the participants on Ward 4 did not allow the patients to conduct their own assessments; the DLDA tool was only used as a basis for dialogue.

“.. It’s a more natural conversation, if I ask the question” So, how does it work for you to read a daily newspaper now, do you get anything out of what you read? “(...) or give some more concrete examples of everyday life, I feel more ... what can I say? ... a little more human ...” Asta, Ward 4.

On Ward 5, all new patients had to fill in a DLDA assessment and later on evaluate the results. It was also used together with occupational therapy investigations. The staff had operationalized the DLDA tool by simply letting patients answer the questions. They did not use the staff assessment form because they found it difficult to assess new patients.

\subsubsection{Relational integration}

Relational integration concerns how the DLDA was understood by the participants, not only regarding awareness of how and when to use the DLDA (knowledge), but also understanding the thoughts of other staff members. On Ward 4, there 
was a need for fresh ideas to be brought forward in relation to individual patients. The participants on Ward 5 believed that one can work with the DLDA in different ways depending on the patient's own motivation and readiness to change. They saw the tool as consisting of major issues that should be broken down and worked with in a stepwise process. The participants on Ward 3 revealed that they selected patients who they thought might benefit from doing an assessment in line with the DLDA.

\subsubsection{Skill-set workability}

Refers to how the DLDA was conducted and distributed. This influenced how the work was defined and divided among the participants. Ward 4 had slightly different ways of applying the tool. One participant let the patient fill in the DLDA, and they discussed the answers immediately afterwards. Another participant let the patient fill in the tool at home before their meeting, in order to save time. One participant revealed that she planned to ask all new patients to answer the questions. Normally the participants on Ward 5 distributed the DLDA to every new patient, which means that the participants did not conduct any assessments themselves. The participants on Ward 3 emphasized the importance of nursing staff and patients being able to sit down and discuss the DLDA on the ward.

“Of course you have to be a little selective about who you give it to.” Karin, Ward 3.

\subsubsection{Contextual integration}

Contextual Integration refers to how the DLDA was incorporated into the social context on the wards under study. Incorporation of the DLDA was a relatively easy process for staff and patients on Ward 5. On this ward, the nursing staff had started using the DLDA after observing an initiated nurse and a patient answering the DLDA on the ward. Thus far, none of the patients had refused to complete or questioned the DLDA. Because none of the participants on the other wards had any statements belonging to this subcategory, this finding can be interpreted as a failure to successfully implement the DLDA tool in the social context on these wards (1-4).

\subsection{Reflexive monitoring}

Reflexive monitoring concerns how the new practice was understood and assessed by the participants. Fewer statements were found in this category - reflexive monitoring with its subcategories systematization; communal appraisal; individual appraisal and reconfiguration - than in the other categories. In fact, only Ward 5 had statements related to all of the subcategories. Participants on Ward 5 assessed the DLDA as a tool with several advantages both from a patient and from a nursing staff perspective. They used it to plan nursing care because it provided a common language for the team. Another advantage was that the tool was used to identify whether the patient's functioning had changed.

\subsubsection{Systematization}

Systematization refers to judgments regarding the DLDA's usefulness and effectiveness. The participants on Ward 5 felt the tool was useful because the nursing staff and patient could use it to plan care based on the patient's needs.

\subsubsection{Communal appraisal}

Communal appraisal concerns the outcomes and values of the DLDA. According to staff on Ward 5, the value of the DLDA tool was that it provided a great deal of information about the patient in a short period of time.

"You can really use it in treatment (...) it’s meaningful.” Irma, Ward 5.

They also found it quick to administer and possible to develop. The DLDA also facilitated working across professional boundaries, according to the nurses on Ward 5.

\subsubsection{I ndividual appraisal}

Individual appraisal refers to the outcomes and values of the DLDA. As mentioned earlier, participants on Ward 5 emphasized the fact that the DLDA provided a common language that different professionals could use. 


\subsubsection{Reconfiguration}

Reconfiguration concerns suggestions from participants that were aimed at modifying and enhancing the utility of the DLDA tool. One respondent was critical to a few questions. One example was question 5b:

... 5b (...) is ... "how would you rate your use of tobacco, alcohol and drugs." Some patients feel that it's assumed that they are using them. “They don't like the question (...) it might be a little offensive (...)” Irma, Ward 5.

\subsection{Data outside coding framework}

Only a few comments could not be coded inside the framework. These rare comments, however, seemed to have a vague impact on the implementation process. The following quotation is an example of such of data:

"I think they'll find more data on patients' functions at the outpatient units, because a lot of patients get passive as soon as they get inside the door on the ward (...)” Malin, Ward 1.

Such comments were mainly assumptions only loosely tied to the influence of the DLDA tool.

\section{Discussion}

The aim of the present study was to highlight the implementation process concerning a new working method in a psychiatric nursing context where the analytic framework was inspired by NPT ${ }^{[23-25]}$. Although the data were not supported by all categories in the NPT framework on all of the participating wards (see Table 1 ), the theory ${ }^{\text {[23-25] }}$ did seem appropriate for this specific study. However, when using NPT ${ }^{[52]}$, the results of the implementation process varied across wards. According to NPT, this variation could be interpreted as different approaches to implementing the DLDA ${ }^{\text {[23-25, 52] }}$. The results showed that just one in five of the participating wards (Ward 5) met the criteria for a successful implementation process (see Table 3). This finding is consistent with previous studies revealing the difficulties associated with implementing new practices in healthcare ${ }^{[22-25,54]}$.

Table 3. An overview of the implementation process related to NPT for each ward

\begin{tabular}{|c|c|c|c|c|c|c|c|c|c|c|c|c|c|c|c|c|}
\hline Sub category & D & CS & IS & IM & I & $\mathbf{E}$ & $\mathbf{L}$ & A & IW & $\mathbf{R I}$ & SW & CI & $\mathbf{S}$ & $\mathbf{C A}$ & IA & $\mathbf{R}$ \\
\hline Ward 1 & $\mathrm{x}$ & $\mathrm{x}$ & $\mathrm{x}$ & $\mathrm{x}$ & $\mathrm{x}$ & $\mathrm{x}$ & $\mathrm{x}$ & $\mathrm{x}$ & & & & & & & & \\
\hline Ward 2 & $\mathrm{x}$ & $\mathrm{x}$ & $\mathrm{x}$ & $\mathrm{x}$ & $\mathrm{x}$ & $\mathrm{x}$ & $\mathrm{x}$ & $\mathrm{x}$ & & & & & & & & \\
\hline Ward 3 & $\mathrm{x}$ & $\mathrm{x}$ & $\mathrm{x}$ & $\mathrm{x}$ & $\mathrm{x}$ & $\mathrm{x}$ & $\mathrm{x}$ & $\mathrm{x}$ & $\mathrm{x}$ & $\mathrm{x}$ & $\mathrm{x}$ & & & & & \\
\hline Ward 4 & $\mathrm{x}$ & $\mathrm{x}$ & $\mathrm{x}$ & $\mathrm{x}$ & $\mathrm{x}$ & & $\mathrm{x}$ & $\mathrm{x}$ & $\mathrm{x}$ & $\mathrm{x}$ & $\mathrm{x}$ & & & & & \\
\hline Ward 5 & $\mathrm{x}$ & $\mathrm{x}$ & $\mathrm{x}$ & $\mathrm{x}$ & $\mathrm{x}$ & $\mathrm{x}$ & $\mathrm{x}$ & & $\mathrm{x}$ & $\mathrm{x}$ & $\mathrm{x}$ & $\mathrm{x}$ & $\mathrm{x}$ & $\mathrm{x}$ & $\mathrm{x}$ & $\mathrm{x}$ \\
\hline
\end{tabular}

Note. Coherence (D-IM), Cognitive Participation (I-A), Collective Action (IW-CI), Reflexive Monitoring (S-R).

Coherence and subcategory of; D = Differentation; CS = Communual specification; IS = Individual specification; IM = Internalized meaning; Cognitivie Participation and subcategory of: I = Initiation; E = Enrolement; L = Legitimation; A = Activation of DLDA; Collective Action and subcategory of; IW = Interactional workability; RI = Relational Integration; SW = Skill-set Workability; CI = Contextual Integration; Reflexive Monitoring and subcategory of; $\mathrm{S}$ = Systematization; $\mathrm{CA}$ = Communal appraisal; IA = Individual appraisal; $\mathrm{R}$ = Reconfiguration.

NPT consists of three core problems, where Ward 5 succeeded in activating this new assessment tool (implementation) as well as in routinely incorporating the DLDA tool (embedding) on the ward. Whether this new model will persist over time (integration) remains to be seen, but the current situation seems promising ${ }^{[25]}$. With some restrictions suggested by May et al., NPT could be used to predict the outcome of implementation processes ${ }^{[25]}$. Alharbi et al. mean that NPT has a weakness in the sense that the theory does not take into account the time dimension of implementation processes ${ }^{[38]}$, a notion that is also supported by the present results. Participants on some of the studied wards suggested that more time is required in relation to the implementation process. The idea that implementation processes require a long-term view if they are to succeed was also confirmed by the poor implementation results in Lauritzen et al.'s study ${ }^{[28]}$. The implementation process on the other wards (1-4) under study here ranged from just meeting the criteria for cognitive participation to nearly 
completing the criteria for collective action (see Table 3). This could be seen as a failure to implement, embed and integrate the DLDA tool on those wards ${ }^{[25]}$. The difficulty of introducing new models could be explained by the need to de-implement previously introduced models that had failed. Organizational fragments of previous models remain in the organization and interfere with the introduction of new models ${ }^{[55]}$.

The enrolment of participants on the wards under study revealed difficulties in implementing the new practice. One explanation may be that co-workers were not convinced of the benefits of the new working method, thus resulting in a defensive stance against the new system. This might be due to high investment costs, i.e. the new method was resourceand time-consuming ${ }^{[18,33,56]}$. This finding is in accordance with previous results suggesting that implementing new methods, models or practices in mental healthcare or healthcare is typically difficult ${ }^{[15,22-25]}$. According to Rashid et al., it is important to understand the organizational culture before initiating projects towards change ${ }^{[57]}$. The cultural characteristics identified prior to the implementation process indicated that Ward 1, 2 and 4 were characterized by flexibility, cohesion and belongingness - a cultural profile that is beneficial to implementation processes, according to Carlström and Ekman ${ }^{[58]}$. In contrast, Alharbi et al. suggest that a cultural profile characterized by stability and control seems to be a better precondition for sustaining implemented models than this one marked by flexibility, cohesion and belongingness ${ }^{[59]}$. Such a culture was identified on Ward 3, which consisted of mixed cultural profiles. In this respect, Ward 3 could be interpreted as a workplace where it is possible for changes to be sustained over time, but also as a workplace with a high degree of willingness to change ${ }^{[42,60]}$.

Resistance to change on the participating wards was generally low. Even if a previous study on these wards ${ }^{[42]}$ did not show that they were dominated by change resistant cultures, the present results of this present study suggest that there are indeed additional inhibiting factors that affected the outcomes of implementation of the DLDA tool ${ }^{[15,61]}$. Besides cultural characteristics, resistance to change and its impact on implementation processes ${ }^{[14,15,34,62]}$ as well as time constraints and co-workers defending the old system ${ }^{[18,33,38,56]}$, the present study reveals a number of other factors that may have affected the implementation processes: time pressure; heavy workload; stress; lack of routines in using the new tool; lack of nursing staff as well as lack of time. Lack of time is also consistent with the findings of Grol and Wensing, who mean that time-consuming, complex interventions may affect the implementation process in nursing ${ }^{[63]}$. An additional inhibiting factor could be the choice of implementation strategy. Based on May and Finch's findings, it might be reasonable to predict that the process of implementing the DLDA will further decline over time on Ward 1-4 ${ }^{[52]}$. Determining whether or not this prediction will be borne out requires further studies. A report from the Swedish Association of Local Authorities and Regions argued that, with regard to Swedish psychiatric inpatient care, the content and standard of care varies widely. The report called for more research on evidence-based methods that take advantage of the patient's own resources ${ }^{[64]}$. The present study is an example of such research, but the results suggest that it is not easy to implement new working methods, however promising they may seem, because implementation processes are complex and multifaceted.

The category of coherence did show that the DLDA tool had meaningful qualities that differed from other tools and instruments used on the wards ${ }^{[52]}$. It also revealed a change in the social context on Ward 1 and 2. During the study period, the participants and their co-workers on Ward 1 and 2 began to focus on patients' functions, which can be interpreted as a mindset inspired by the ICF ${ }^{[65]}$, which is both a classification and a conceptual model. The classification represents a comprehensive taxonomy, describing various factors from multiple perspectives on an individual's ability to function. The conceptual model, on the other hand, is used on a more general level to gather information about the functioning of the individual ${ }^{[66]}$. The present results could be interpreted as indicating that staff on Ward 1 and 2 realized the new model as an ideal rather than as a practice. This indicates that the training sessions in the ICF and DLDA were effective on Ward 1 and 2, where the participants not only viewed patients from a medical and diagnostic perspective, but also took into account their functioning. This may have been influenced by the organizational culture on both of these wards, which was characterized by flexibility, belongingness and cohesion ${ }^{[42]}$. In contrast, staff on Ward 3 maintained the diagnostic perspective. According to Hummelvoll and Severinsson, the medical and diagnostic perspective is still predominant in nursing ${ }^{[67]}$. However, from an ideological perspective, nurses take a more hermeneutic approach 
characterized by humanistic and holistic values ${ }^{[68]}$. The conceptual model of the ICF ${ }^{[5,6]}$ could fit well into Hummelvolls and Severinsson's ${ }^{[67]}$ description of the ideological perspective of nurses, as the ICF includes several aspects of health and was not designed solely for people with disabilities. The present findings would seem to indicate that the ICF could be used as an aid to merge nurses' ideological foundation with their everyday practice ${ }^{[69,70]}$. In that sense, the DLDA could even been used as an aid in improving psychiatric care. Another quality of the DLDA tool was that patients seemed to appreciate having structured dialogues with the nursing staff. This is also consistent with the results of Koivistos et al.'s study, which showed that patients who had recovered from a psychosis often experienced interactions with nursing staff as unorganized, resulting in patients not being able to predict or understand the purpose of dialogues ${ }^{[71]}$.

\section{Limitations}

Due to the negative effect of staff turnover, only two staff members from Ward 2 and 3 participated in the focus groups interviews post-implementation (see Table 2). This may have resulted in fewer varieties of perspectives ${ }^{[72]}$ that might have affected the results. The reason why no other wards were included in this study depends on internal organizational difficulties. Some of the wards in the clinic suffered from high staff turnovers and fiscal limitations. The wards included into the study were selected by the management in collaboration with the research team in order to not put extra burden on wards in difficulties. The fact that ward 5 already was familiar with patient assessments may have affected the outcome of the study. The transferability of the results related to the implementation process is another limitation; it is not possible to generalize the findings outside the Swedish hospital studied, as focus groups interviews only provide knowledge about the studied groups ${ }^{[45]}$. A fourth limitation is that the participating units consisted of both inpatient and outpatient wards, and it is difficult to compare or equate inpatient with outpatient care ${ }^{[64]}$. Further studies are required before coming to any conclusions regarding the similarities and differences between Swedish inpatient and outpatient psychiatric care and the connection to organizational characteristics.

\section{Conclusions}

The results showed the progress of implementation on the participating wards, where only one ward seemed to successfully implement this new model. Further studies are required to follow up on the results and to see whether they are sustained over time. The implementation process seemed to be influenced by factors besides cultural characteristics and resistance to change - factors such as: time pressure; heavy workload; stress; lack of routines in using the tool; lack of nursing staff as well as lack of time. Even if the participants agreed with the intention of the model, they were nonetheless reluctant to apply it in practice. The results also revealed some of the pros and cons of the DLDA tool. This would seem to indicate that the DLDA tool has meaningful qualities that may be transferable outside the studied hospital. Henceforth, the DLDA tool could: (1) serve as an aid in the psychiatric nursing context, (2) be used to aid nurses in their responsibility for quality assurance, (3) and be used in development of psychiatric nursing care. Clearly, further studies are required. The NPT framework seemed appropriate for highlighting and selecting important factors that might have affected the process of implementing the DLDA tool at the psychiatric hospital under study. However, the fact that NPT does not seem to take the time dimension into account when investigating the implementation process is considered a limitation of the theory.

\section{Competing interests}

The authors declare that they have no competing interests.

\section{Acknowledgements}

The authors would like to thank the studied psychiatric clinic and the participating wards. A special thanks to all key participants, for their commitment and participation in the study. The authors would also like to thank the anonymous reviewers for their valuable comments to the paper. 


\section{References}

[1] Appelbaum, S.H., Wohl, L. Transformation or change: some prescriptions for health care organizations. Managing Service Quality. 2000; 10 (5): 279-298. http:// dx.doi.org/10.1108/09604520010345768

[2] Pavolini, E., Ranci, C. Restructuring the welfare state: reforms in long-term care in Western European countries. Journal of European Social Policy. 2008; 18 (3): 246-259. http:// dx.doi.org/10.1177/0958928708091058

[3] Berlin, J.M., Carlström, E.D. The yellow line: a critical study of the symbolic value of artefacts in health care teams. Cognition, Technology \& Work. 2010; 12 (4): 251-261. http:// dx.doi.org/10.1007/s10111-009-0136-5

[4] Johansson, C., Åström, S., Kauffeldt, A., Carlström, E. Daily Life Dialogue Assessment in Psychiatric Care- Face Validity and Inter-Rater Reliability of a Tool Based on the International Classification of Functioning, Disability and Health. Archives of Psychiatric Nursing. 2013; 27: 306-311. http://dx.doi.org/10.1016/j.apnu.2013.08.005

[5] The Swedish National Board of Health and Welfare (Socialstyrelsen). Swedish version of International Classification of Functioning, Disability and Health (ICF). [In Swedish Klassifikation av funktionstillstånd, funktionshinder och hälsa]. Stockholm: Socialstyrelsen. 2003.

[6] World Health Organization. International Classification of Functioning, Disability and Health (ICF). Available from: http://www.who.int/classifications/icf/en/. 2001

[7] De Jager, P. Resistance to change: a new view of an old problem. The Futurist. 2001; 35 (3): 24-7.

[8] Oreg, S. Resistance to change: Developing an individual differences measure. Journal of applied Psychology. 2003; 88 (4): 680-93. http:// dx.doi.org/10.1037/0021-9010.88.4.680

[9] Lowe, A., McIntosh, A. Knowledge management in a New Zealand tree farming company. Ambiguity and resistance to the “technology solution”. Journal of Organizational Change Management. 2007; 20 (4): 539-58. http://dx.doi.org/10.1108/09534810710760072

[10] Wilson, V.J., McCormack, B.G., Ives, G. Understanding the workplace culture of a special care nursery. Journal of Advanced Nursing. 2005; 50(1): 27-38. http:// dx.doi.org/10.1111/j.1365-2648.2004.03346.x

[11] Saame, I., Reino, A., Vadi, M. Organizational culture based on the example of an Estonian Hospital. Journal of Health Organization and Management. 2011; 25(5): 526-48. http:// dx.doi.org/10.1108/14777261111161879

[12] Berlin, J., Carlström, E. Cultural Camouflage - A critical study of how artefacts are camouflaged and mental health policy subverted. Journal of Health Planning and Management. http://dx.doi.org/10.1002/hpm.2210 (E-pub, Online). 2013.

[13] Benders, J., Van Hootegem, G. Teams and their context: moving the team discussion beyond existing dichotomies. Journal of Management Studies. 1999; 36(5): 609-28. http://dx.doi.org/10.1111/1467-6486.00151

[14] Holmberg, L. Health-care processes: a study of medical problem solving in the Swedish health-care organization. Lund: Lund University Press. 1997.

[15] Van Achterberg, T., Schoonhoven, L., Grol, R. Nursing implementation science: How evidence-Based nursing requires Evidence-Based Implementation. Journal of nursing scholarship. 2008; 40(4): 302-310. http://dx.doi.org/10.1111/j.1547-5069.2008.00243.x

[16] Fixsen, D.L., Naoom, S.F., Blase, K.A., Friedman, R.M. Implementation Research: A Synthesis of the Literature. Tampa (FL): University of South Florida, Louis de la Parte Florida Mental Health Institute. 2005.

[17] Garpenby, P. Perspektiv på implementering. [Perspectives on implementation] In P. Nilsen (Eds.), Implementering:Teori och tillämpning inom Hälso- \& sjukvård (pp.27-49) [Implementation: Theory and Application in Healthcare]. Lund: Studentlitteratur. 2010.

[18] Greenhalgh, T., Robert, G., Bate, P. Macfarlane, F., Kyriakidou, O. Diffusion of Innovations in Health Service Organisations- A Systematic Literature Review. Malden Massachusetts: Blackwell Publishing. 2005. http://dx.doi.org/10.1002/9780470987407

[19] Severinsson, E. Nursing research in theory and practice - is implementation the missing link? Journal of Nursing Management. 2012; 20: 141-143. http://dx.doi.org/10.1111/j.1365-2834.2012.01387.x

[20] Nilsen, P., Roback, K. Implementering, kunskap och lärande- en begreppsmässig plattform. [Implementation, knowledge and learning- a conceptual platform] In P. Nilsen (Eds.), Implementering:Teori och tillämpning inom Hälso- \& sjukvård (pp.51-69). [Implementation: Theory and Application in Healthcare]. Lund: Studentlitteratur. 2010.

[21] Drake, R.E., Goldman, H.H., Leff, H.S., Lehman, A.F., Dixon, L., Mueser, K.T., et al. Implementing Evidence-Based Practices in Routine Mental Health Service Settings. Psychiatric Services. 2001; 52(2): 180. http://dx.doi.org/10.1176/appi.ps.52.2.179

[22] Torrey, W.C., Drake, R.E., Dixon, L., Burns, B.J., Flynn, L., Rush., A.J., et al. Implementing evidence-based practices for persons with severe mental illnesses. Psychiatric Services. 2001; 52(1): 45-50. http://dx.doi.org/10.1176/appi.ps.52.1.45

[23] May, C. A rational model for assessing and evaluating complex interventions in health care. BMC Health Services Research. 2006; 6(86). http:// dx.doi.org/10.1186/1472-6963-6-86 
[24] May, C., Finch, T., Mair, F., Ballini, L., Dowrick, C., Eccles, M., et al. Understanding the implementation of complex interventions in health care: the normalization process model. BMC Health Services Research. 2007; 7(148). http://dx.doi.org/10.1186/1472-6963-7-148

[25] May, C.R., Mair, F., Finch, T., MacFarlane, A., Dowrick, C., Treweek, S., et al. Development of a theory of implementation and integration: Normalization Process Theory. Implementation Science. 2009; 4(29). http://dx.doi.org/10.1186/1748-5908-4-29

[26] Arvidsson, B., Löfgren, H., Fridlund, B. Psychiatric nurse's conception of how a group supervision programme in nursing care influences their professional competence: a 4-year follow-up study. Journal of Nursing Management. 2001; 9: 161-171. http://dx.doi.org/10.1046/j.1365-2834.2001.00220.x

[27] Chan, S., Mackenzie, A., Tin-Fu, D., Ka-yi Leung, J. An evaluation of the implementation of case management in the community psychiatric nursing service. Journal of Advanced Nursing. 2000; 31(1): 144-156. http://dx.doi.org/10.1046/j.1365-2648.2000.01250.x

[28] Lauritzen, C., Reedtz, C., Van Doesum, K.T., Martinussen, M. Implementing new routines in adult mental health care to identify and support children of mentally ill parents. BMC health services research. 2014; 14(1): 58. http://dx.doi.org/10.1186/1472-6963-14-58

[29] Wiegand, N.M., Belting, J., Fekete, C., Gutenbrunner, C., Reinhardt, J.D. All talk, no action: the global diffusion and clinical implementation of the international classification of functioning, disability, and health. American Journal of Physical Medicine \& Rehabilitation. 2012; 91(7): 550-560. http://dx.doi.org/10.1097/PHM.0b013e31825597e5

[30] Carlfjord, S. Teorianvändning vid forskning som rör implementering inom hälso-och sjukvården.[ Use of theories in research related to implementation in healthcare] In P. Nielsen (Eds.), Implementering teori och tillämpning inom hälso och sjukvården [Implementation: Theory and Application in Healthcare]. Lund: Studentlitteratur. 2010; 91-105.

[31] Rogers, E.M. Diffusion of innovations. New York: Free Press. 1983.

[32] Rogers, E.M. Diffusion of innovations (4th ed). New York: Free Press. 1995.

[33] Rogers, E.M. Diffusion of innovations (5th ed). New York: Free Press. 2003.

[34] Carlfjord, S., Andersson, A., Nilsen, P., Bendtsen, P., Lindberg, M. The importance of organizational climate and implementation strategy at the introduction of a new working tool in primary health care. Journal of Evaluation in Clinical Practice. 2010; 16: 1326-1332. http://dx.doi.org/10.1111/j.1365-2753.2009.01336.x

[35] Jansson, I., Pilhammar, E., Forsberg, A. Factors and conditions that have an impact in relation to the successful implementation and maintenance of individual care plans. Worldviews on Evidence-based Nursing. 2011; 8(2): 66-75. http://dx.doi.org/10.1111/j.1741-6787.2010.00195.x

[36] Rycroft-Malone, J. The PARISH Framework - A Framework for guiding the implementation of evidence-based practice. Journal of nursing care quality. 2004; 19(4): 297-304. PMid: 15535533. http://dx.doi.org/10.1097/00001786-200410000-00002

[37] Rycroft-Malone, J., Harvey, G., Seers, K., Kitson, A., McCormack, B., Titchen, A. An exploration of the factors that influence the implementation of evidence into practice. Journal of clinical nursing. 2004; 13: 913-924. http://dx.doi.org/10.1111/j.1365-2702.2004.01007.x

[38] Alharbi, T.S., Carlström, E., Ekman, I., Olsson, L.E. Implementation of person-centred care: management perspective. Journal of Hospital Administration. 2014; 3(3). http://dx.doi.org/10.5430/jha.v3n3p107

[39] Cieza, A., Chatterji, S., Andersen, C., Cantista, P., Herceg, J.M., Stucki, G., et al. ICF core sets for depression. Journal of Rehabilitation Medicine Supplement. 2004; 44: 128-134. http://dx.doi.org/10.1080/16501960410016055

[40] The Swedish National Board of Health and Welfare. (Socialstyrelsen, 2003b). (n.d.). About ICF Checklist. Version 2.1 a. Available from: http://www.socialstyrelsen.se/klassificeringochkoder/koderfunktionshinder/Documents/ICF_checklista.pdf

[41] World Health Organization. World Health Organization Disability Assessment Schedule II (WHODAS II). Available from: http://www.who.int/classifications/icf/whodasii/en/. 2001

[42] Johansson, C., Åström, S., Kauffeldt, A., Helldin, L., Carlström, E. Culture as a predictor of resistance to change. Health Policy. 2014; 114: 156-162. http://dx.doi.org/10.1016/j.healthpol.2013.07.014

[43] Morgan, D.L. Focus Groups. Annual Review of Sociology. 1996; 22: 129-152. http://dx.doi.org/10.1146/annurev.soc.22.1.129

[44] Wibeck, V. Fokusgrupper om fokuserade gruppintervjuer som undersökningsmetod. [Focus groups about focused group interviews as research method] Lund: Studentlitteratur. 2010.

[45] Sim, J. Collecting and analysing qualitative data: issues raised by the focus group. Journal of Advanced Nursing. 1998; 28(2): 345-352. http://dx.doi.org/10.1046/j.1365-2648.1998.00692.x

[46] Webb, C., Kevern, J. Focus groups as a research method: a critique of some aspects of their use in nursing research. Journal of Advanced Nursing. 2001; 33(6): 798-805. http://dx.doi.org/10.1046/j.1365-2648.2001.01720.x

[47] Carey, M.A., Smith, M.W. Capturing the group effect in focus groups: A special concern in analysis. Qualitative Health Research. 1994; 4(1): 123-127. http://dx.doi.org/10.1177/104973239400400108 
[48] Kitzinger, J., Barbour, R.S. Introduction: the challenge and promise of focus groups. Developing focus group research: Politics, theory and practice. London: Sage Publication Ltd. 1999; 1-20.

[49] Ruff, C.C., Alexander, I.M., McKie, C. The use of focus group methodology in health disparities research. Nursing outlook. 2005; 53(3): 134-140. PMid: 15988450. http://dx.doi.org/10.1016/j.outlook.2005.03.010

[50] Doody, O., Slevin, E., Taggart, L. Focus group interviews. Part 3: analysis. British Journal of Nursing. 2013; $22(5): 266-269$. PMid: 23545552. http://dx.doi.org/10.12968/bjon.2013.22.5.266

[51] Hsieh, H.F., Shannon, S.E. Three approaches to qualitative content analysis. Qualitative Health Research. 2005; 15(9): 1277-1288. http://dx.doi.org/ 10.1177/1049732305276687

[52] May, C., Finch, T. Implementing, embedding, and integrating practices: an outline of normalization process theory. Sociology. 2009; 43(3): 535-554. http://dx.doi.org/10.1177/0038038509103208

[53] SFS. Lag 2003:460 om etikprövning av forskning som avser människor. [Law 2003:460 about the ethical review of research involving humans]. Stockholm: Riksdagen. 2003.

[54] Berlin, J. Synchronous work- myth or reality? - A critical study of teams in health and medical care. Journal of Evaluation in Clinical Practice. 2010; 16(4): 1314-1321. http://dx.doi.org/10.1111/j.1365-2753.2009.01334.x

[55] Berlin, J., Carlström, E. Traditions challenged by trends. A health care industry in metamorphosis. [In Swedish: Trender som utmanar traditioner. En hälso-och sjukvård i metamorfos]. Scandinavian Journal of Public Administration. 2013; 16(2): 3-23. Available from: www.sjpa.gu.se

[56] Greenhalgh, T., Robert, G., MacFarlane, F., Bate, P., Kyriakidou, O. Diffusion of Innovations in Service Organizations: Systematic Review and Recommendations. The Milbank Quarterly. 2004; 82(4): 581-629. PMid: 15595944. http://dx.doi.org/10.1111/j.0887-378X.2004.00325.x

[57] Rashid, M.Z.A., Sambasivan, M., Rahman, A.A. The influence of organizational culture on attitudes toward organizational change. Leadership \& organization development Journal. 2004; 25(2): 161-179. http://dx.doi.org/ 10.1108/01437730410521831

[58] Carlström, E., Ekman, I. Organizational culture and change: implementing person-centred care. Journal of Health organization and Management. 2012; 26(2): 175-191. http://dx.doi.org/10.1108/14777261211230763

[59] Alharbi, T.S.J., Ekman, I., Olsson. L.E., Dudas, K., Carlstrom, E. Organizational culture and the implementation of person centered care: results from a change process in Swedish hospital care. Health Policy. 2012; 108(2): 294-301. http://dx.doi.org/10.1016/j.healthpol.2012.09.003

[60] Glisson, C. Assessing and changing organizational culture and climate for effective services. Research on social work practice. 2007; 17(6): 736-747. http://dx.doi.org/10.1177/1049731507301659

[61] Seren, S., Baykal, U. Relationships between change and organizational culture in hospitals. Journal of Nursing Scholarship. 2007; 39(2): 191-197. http://dx.doi.org/10.1111/j.1547-5069.2007.00166.x

[62] Benders, J., Van Hootegem, G. Teams and their context: moving the team discussion beyond existing dichotomies. Journal of Management Studies. 1999; 36(5): 609-28. http://dx.doi.org/10.1111/1467-6486.00151

[63] Grol,R., Wensing, M. Effective implementation: A model. In R.Grol., M. Wensing, \& M. Eccles (Eds.), Improving patient care: The implementation of change in clinical practice. London: Elsevier. 2005.

[64] The Swedish Association of Local Authorities and Regions. Kartläggning av den psykiatriska heldygnsvården. [A survey of the psychiatric inpatient care]. Stockholm: Sweden. Available from www.skl. se. 2010.

[65] Pless, M., Granlund, M. Handbok i att använda ICF och ICF-CY. [Manual in using ICF and ICF-CY]. Lund: Studentlitteratur. 2011.

[66] Pless, Adolfsson., Klang. ICF som tankemodell. [ICF as a conceptual model] In M. Pless., \& M. Granlund (Eds.), Handbok i att använda ICF och ICF-CY (pp.19-35) [Manual in using ICF and ICF-CY]. Lund: Studentlitteratur. 2011.

[67] Hummelvoll, J., Severinsson, E. Imperative ideals and the strenuous reality: focusing on acute psychiatry. Journal of Psychiatric and Mental Health Nursing. 2001; 8(1): 17-24. http://dx.doi.org/10.1111/j.1365-2850.2001.00346.x

[68] Nyström, M. Ett liv på egna villkor vård och omsorg vid psykiska funktionshinder [A life on own terms, healthcare for mental disabilities]. Stockholm: Natur och Kultur. 2003.

[69] Kearney, P.M., Pryor, J. The international classification of functioning, disability and health (ICF) and nursing. Journal of Advanced Nursing. 2004; 46(2): 162-170. PMid: 15056329. http://dx.doi.org/10.1111/j.1365-2648.2003.02976.x

[70] Van Achterberg, T., Holleman, G., Heijnen Kaales, Y., Van der Brug, Y., Roodbol, G., Stallinga, H.A., et al. Using a multidisciplinary classification in nursing: the International Classification of Functioning Disability and Health. Journal of advanced nursing. 2005; 49(4): 432-441. http://dx.doi.org/ 10.1111/j.1365-2648.2004.03307.x

[71] Koivisto, K., Janhonen, S., Väisänen, L. Patients’ experiences of being helped in an inpatient setting. Journal of psychiatric and mental health nursing. 2004; 11(3): 268-275. http://dx.doi.org/10.1111/j.1365-2850.2003.00705.x

[72] Rabiee, F. Focus-group interview and data analysis. Proceedings of the nutrition society. 2004; 63(04): 655-660. http://dx.doi.org/doi:10.1079/PNS2004399 